\title{
FROM POSTS TO PATTERNS: A METRIC TO CHARACTERIZE DISCUSSION BOARD ACTIVITY IN ONLINE COURSES
}

\author{
Catherine A. Bliss and Betty Lawrence \\ Center for Distance Learning \\ Empire State College
}

\begin{abstract}
Asynchronous text based discussion boards are included in many online courses, however strategies to compare their use within and between courses, from a disciplinary standpoint, have not been well documented in the literature. The goal of this project was to develop a multi-factor metric which could be used to characterize discussion board use in a large data set ( $n=11,596$ message posts) and to apply this metric to all Mathematics courses offered in the January 2008 term by the Center for Distance Learning at Empire State College. The results of this work reveal that student participation rates, quantity of student posts, quality of student posts and the extent of threading are well correlated with instructor activity.
\end{abstract}

\section{KEYWORDS}

Distance Learning, Discussion Board, Asynchronous Learning, Student Participation, Instructor Roles, Educationally Valuable Talk, Metric, Mathematics, Online Learning

\section{BACKGROUND}

Online learning programs have grown tremendously in the past 15 years. As these programs continue to grow, research in the areas of instructional design and course evaluation have also grown. One area of online course design, delivery and evaluation that has received a particularly high level of attention is the use of asynchronous text based discussion. Providing a framework for the purpose of discussion boards in an online course, Garrison, Anderson and Archer's [1] model of "Communities of Inquiry" for online learning environments place student learning at the intersection of social, cognitive, and teaching presence. This model has been extended [2,3] by overlaying interaction with peers, interaction with content and interaction with instructors with social, cognitive and teaching presence, respectively. At the core of this extended model are Chickering and Gamson's "Seven Principles for Good Practice in Undergraduate Education” [4].

\section{A. Social presence}

Social presence has been defined as "the ability of learners to project themselves socially and affectively into a community of inquiry" [5, p. 50]. As such, discussion boards are a place where learners can engage themselves socially and the class may develop a sense of community [6, 7]. For adult learners who may not have the traditional support networks that younger students may have, and for distance learners, who are separated by time and physical space, the development of peer support networks via discussion boards within an online course may be particularly important.

Research with students in the State University of New York's s Learning Network supports the notion 
that students benefit from this social interaction in online courses. Researchers $[8,9]$ found a positive correlation between students' perceived learner-learner interactions and students' satisfaction with their online course. These authors also found positive correlations between students' perceived learner-learner interactions and their perceived learning. This suggests that building the social presence and encouraging learner-learner interactions may be one way in which discussion boards enhance the online learning experience.

\section{B. Cognitive Presence}

Discussion boards can be used to facilitate students' co-construction of knowledge, engagement in higher order thinking, and the development of critical thinking skills [10,11, 12]. Discussion boards can be a place where students negotiate meaning of course content and practice skills before independent mastery is expected.

Constructivist learning theory suggests that knowledge is constructed by learners, rather than transmitted from teacher to student. According to Vygotsky’s Social Learning Theory, learning occurs through students' social interactions [13]. The Zone of Proximal Development is defined as the zone between the abilities which students can perform independently and those which require the guidance of an instructor. Vygotsky concluded that this is where learning occurs. This theory suggests that discussion boards may be an opportunity where students may bridge the gap between existing skills and new skills to be acquired.

Discussion boards also enhance student learning in an online course because they are an area where higher order cognitive processing may be developed. In 1956, Benjamin Bloom described six of levels for higher order cognitive processing and suggested that engagement in the higher levels would allow a greater transfer of learning beyond the course context [14]. Students may often operate in the first three levels of cognitive processing (knowledge, comprehension and application) via individually based homework assignments, projects, and assessments. However, it is a more challenging task to engage students in the upper three levels (analysis, synthesis and evaluation). It is precisely through class discussions that students may argue, evaluate, assess, construct, design, propose, compare and analyze course content. "Electronic discussion changes the focus of the learning process, replacing the single view of the instructor with the diversity of views from different students” [10, p. 41]. It is within these levels where a deeper understanding of course content can be cultivated, thus allowing students to "package and bundle" course content to be used in their professional and personal lives. Thus, discussion boards in an online course may be a place where students can engage in higher order thinking.

Discussion boards have a role in teaching critical thinking skills. As an instructional tool, they can encompass the best elements of writing assignments and in class discussions [10]. In an online course, an asynchronous text-based discussion board may hold the added advantage of a time-lag between postings. This may lead to greater reflection and enriched discussions as compared to discussions in face-to-face settings $[15,16]$.

Several authors have found support for the theory that discussion board use may support cognitive processing. Work by [2, 8,9, 17] indicates significant positive correlations between perceived discussion board activity and perceived learning. Even more convincing, [17] and [18] found a significant positive correlation between the quantity of student posts and students' scores on final assessments. It is possible that students with particularly good study habits, post frequently to the course and also work efficiently to master course objectives, thus scoring well on final assessments. At the very least, though, discussion boards can support cognition through peer-dialogue and increased learner-content interactions. 


\section{Teaching Presence}

Teaching presence in online courses can be defined as consisting of three roles: "design and organization, facilitating discourse, and direct instruction" [19, p. 1]. Instructors may use several strategies for facilitating discourse, such as "identifying areas of agreement/disagreement, seeking to reach consensus and understanding, encouraging, acknowledging, and reinforcing student contributions, setting the climate for learning, drawing in participants and prompting discussion, and assessing the efficacy of the process" [19, p. 8]. Discussion boards are a place where instructors may facilitate discourse and provide instruction. Instructors may select content and re-focus a discussion that may have diverged from the main topic. Instructors may also set a tone which respects the diversity of ideas, opinions and experiences and which models an appreciation for the love of learning. As such, instructors need to be present in discussions and discussion boards are a place where teaching presence may be demonstrated.

The role of the instructor in facilitating online discussion has been discussed widely in the literature [810, 18-23]. Surprisingly, considerable debate exists in the literature about the role of an instructor in facilitating online discussion. On one side of the debate, there is the belief that the instructor is crucial to facilitating discussion, but should do so without taking over the discussion [7-10, 20, 23]. Some researchers [10] suggest the role of the instructor is to be a "guide on the side," limited to maintaining focus, moving the discussion along and prompting students to reflect on the discussion. In studies examining discussion board activity, [20] and [21] found that "faculty responsiveness" was a salient factor in developing a meaningful online discussion. However, "more is not necessarily better in terms of presence" [21, p. 143]. Instructors who respond too quickly or extensively may shutdown student interaction.

The view that instructors should be active on discussion boards is supported by researchers examining student satisfaction and perceived learning in online courses. Positive correlations have been found between a.) perceived learning and perceived instructor-student interaction [8, 24], b.) the quantity of instructor postings and the quantity of student postings [9], and c.) students' perceived level of interaction with instructors and overall satisfaction for courses [24]. Other researchers [3, 25] have found that the extent to which instructors are perceived to facilitate discussion is correlated with students' satisfaction of online courses and reported learning.

On the other side of the debate is the view that instructors can interfere with student dialogue and actually inhibit discussion quality rather than facilitate it [22, 23]. Although one researcher [22] suggests that instructors' posts can actually shut down discussion between students, this analysis is ad hoc and involves only a single case study. No transcript analysis is included in the report and it is not possible to determine if it is the type, rather than the quantity of instructor posts that may be correlated with less dialogue. The conclusions drawn by [23] are also problematic. These researchers found that high percentages of instructor posts were correlated with low quantities of student posts and concluded that instructors may be "shutting down" discussions. This index is problematic because in the case of large numbers of student posts, the percentage of instructor posts would be small, simply because the total number of posts is large. Thus, the need for a new measure is apparent.

\section{DEVELOPING A METRIC FOR ASSESSING DISCUSSION BOARD ACTIVITY}

Several researchers have suggested methods for measuring discussion board activity. Some have suggested multi-factor metrics [18, 21, 26-28], while others have specifically focused on participation $[23,29,30]$, the role of instructors [3, 19, 23, 26], quantity of student posts [17, 18, 32], the quality of 
discussion [11, 28, 33-35], the discussion board prompt [36-39], guidelines posted by the instructor [40] and feedback $[7,44]$.

One of the difficulties in measuring discussion board activity revolves around the multitude of factors which may affect discussion board activity (i.e. course design, instructional approach, learner specific characteristics). The other difficulty often revolves around the need for detailed and comparable results. Most of the work presented in the literature thus far has focused on a single case study or a small handful of courses, analyzed in a cross case study analysis [21]. The goal of this paper is to propose a discussion board metric and to apply this metric to online course offerings in one discipline. This work is valuable in that most of the metrics reported in the literature have dealt with data sets on the order of 1000 message posts or less. The metric described in this paper was applied 11,596 message posts and thus can serve as a tool to analyze differences between courses and between sections of the same course.

\section{A. Student Participation}

For this paper, participation is defined as the percent of enrolled students who decide to post to a discussion board. Participation rate is an important measure to include in designing a discussion board metric and is distinct from the quantity of student posts. In an ideal setting, all students who enroll in an online course will complete the course and all currently enrolled students will engage in all learning activities. In practice, this is not the case. Thus, it is informative to examine participation rates, both within a course and between courses.

This definition is an improvement over previous attempts to quantify participation. Many authors use quantity of posts and participation interchangeably. This blurs the distinction between the proportion of student using the discussion board (participation) and how "vocal" students are once they decide to participate (quantity). By examining participation rates, it may be possible to identify areas in need of revision.

\section{B. Quantity of Student Postings}

The quantity of student posts is a common and usually straightforward measure to gather from learning management system software. One approach, as demonstrated by [21] in a cross case study approach, uses the mean number of messages per forum as an indicator for the quantity of posts. Although this measure is useful in a small case study analysis, this index could be misleading in comparing a large number of courses. For example, a mean value of twelve messages per forum could represent very different quantities of posts, depending on whether these posts were made by twelve students or four students.

Another approach for measuring quantity of student postings is to calculate the number of student responses divided by the number of students in the course [9, 17, 23, 31, 32]. Although this index standardizes quantity of posts by course size, it is misleading in that not all enrolled students choose to participate in every discussion. The index for quantity of student posts could be improved by using the "active" students in a discussion board rather than enrolled.

\section{Quality of Student Postings}

Two broad strategies of tools to examine the quality of student postings exist in the literature: rubrics and content analysis. Rubrics are often included in a course to define the expectations for high quality 
discussion board participation. Several examples of discussion board rubrics exist in the literature [7, 27, 33, 36]. Content analysis is a method of coding the content of discussion board postings and is most useful for studying patterns of interactions for research purposes. Several methods for content analysis have been presented in the literature [15, 32, 34, 35, 40, 46].

Using these frameworks for assessing quality of discussion transcripts is problematic because of the amount of time needed to score a large number of discussion posts and issues of inter-rater reliability should more than one rater be used. For example, in this study, 335 message boards were analyzed. To apply a detailed coding scheme would have required two researchers working full-time (40 hours/week) for approximately a year and a half. Most departments who wish to conduct a program review do not have these sorts of resources to allocate. Inter-rater reliability can also cause problems in producing reliable data in discussion board analysis [38].

Attempts to define the "quality" of student posts through a broader lens do not lend themselves well to course review and supervision. For example, [26, p. 266] defines quality of student posts as "the extent to which the message covers the topic that the course experts have identified as significant and the depth (granularity) to which the topics have been explored." This definition is highly subjective and is difficult to quantify. Another attempt, made by [18] defines quality as clear or unclear. Problematically, a post may be clear, but clearly off-topic. Thus, the use of a new paradigm for "quality" is proposed here for inclusion in a multi-factor metric.

A more useful distinction of "quality" posts can be made by determining whether a post is educationally valuable or educationally less valuable. Educationally valuable talk (EVT) is defined by

"a particular interaction pattern in online discussion threads characterized as dialogic exchanges whereby participant collaboratively display construction, and at times, critical engagement with the ideas or key concepts that make up the topic of an online discussion, and build knowledge through reasoning, articulations, creativity and reflection” [43, p. 402].

EVT is characterized by seven indicators: exploratory, invitational, argumentational, critical, heuristic, reflective, or interpretive [43]. Educationally less valuable talk (ELVT) may be defined as "talk that lacks substance in regard to critical and meaningful engagement with the formal content or ideas that are discussed in the posts of other in an online discussion” [43, p. 404]. ELVT is characterized by five indicators: affective, judgmental, experiential, reproductional, or miscellaneous [43]. It is worth noting that educationally less valuable talk is still valuable. It may help build the online community and establish trust within the class. From an instructional and supervision standpoint, this paradigm presents an efficient way to classify posts as related to course content and which move the discussion forward (EVT) vs. those posts that are either not related to course content or those which add little to the depth or breadth to the discussion.

Although EVT/ELVT classification scheme contains 12 indicators and 15 sub-indicators, the main classification scheme represents one choice: EVT or ELVT. The distinction between EVT and ELVT is clear and intuitive. Coding discussion board transcripts using this scheme requires one researcher approximately 1 hour to code approximately 72 posts. Thus, depending on the length of the discussion, the coding time for one discussion board may range from 30 minutes to 2 hours. It is evident that more authentic methods of measuring posts' perceived educational value exist (i.e. interviews, journaling), however, the intention here is to assess the percentage of the message posts which address educationally valuable talk (i.e. talk related to the educational content and objectives of the discussion prompt). The goal here is not to make claims about the inherent value of the posts as evidence of learning, but rather to 
provide a metric which can measure the percentage of the discussion which was related to the educational nature of the discussion.

\section{Extent of Threading}

Increased threading represents an original post which has generated increased dialogue. In addition to quantifying the participation rate and the quantity and quality of student posts, the pattern of interaction can provide additional insights into how discussions are being used in a course and how they may be improved.

A common measure of threading is average thread length [18, 21, 23]. The average discussion thread length is calculated by the total number of student postings divided by the total number of discussion threads. This index tends to blur the distinction between posts that are unanswered, posts that are acknowledged and those which result in discussion because it is reported as an average. "Message maps" are another way to analyze interaction patterns [44, 45]. Although this is interesting from an interaction pattern analysis standpoint, it is not appropriate for use in course review and comparing courses to each other. A more useful method of characterizing discussion would be three broad categories: unanswered posts, acknowledged posts, and posts which lead to discussion. Knowing the relative amounts of posts in these distinct categories would provide useful information on how much dialogue occurs within a course.

\section{E. Instructor Presence}

In studies where multiple courses and instructors have been compared, instructor presence has been generally characterized by the quantity of instructor posts and/or the nature of the instructor's posts. Problematically, though, only measuring the number of instructor posts on a discussion board can be misleading. For example, an instructor with four posts on a discussion board with four participating students represents and hence a minimum of four student posts represents a very different level of instructor activity than an instructor with four posts on a discussion board with twenty-five participating students and a minimum of twenty-five student posts. In the former case, the instructor is highly present and in the latter, the instructor is faintly present. One approach has been to categorize instructor presence as high, medium or little or no presence, although these classifications are not well defined [21]. Characterizing the nature instructor presence by other researches is similarly problematic as it is narrative or descriptive in nature [18, 22]. Part of the reason for this is that often, one course taught by the researcher forms the basis of the research study.

Another approach has been to examine the percentage of instructor postings as defined by the number of instructor postings/total number of postings [23]. This index is problematic because in the case of large numbers of student posts, the percentage of instructor posts would be small, simply because the total number of posts is large. Thus, this index for instructor quantity is confounded with student quantity and not useful for discerning correlative relationships between these two variables. An improvement over this measure has been to measure instructor participation as the raw count of instructor responses per enrolled student in the course [9]. Since not all enrolled students participate in every discussion board, an improved measure would be to use "participating students" rather than enrolled students.

\section{F. Expectations \& Guidelines}

Communicating clear expectations sets students up for success [4]. Clear guidelines become even more important in an online course than in a face to face course because of the lack of immediate feedback to students. In a face to face setting, an instructor may provide cues such as eye contact, nods of approval or 
question the student to provide additional information to support their views. Without these cues in an online course, the initial guidelines and subsequent feedback become increasingly important in facilitating quality academic discourse. Failure to include clear guidelines obscures the definition of successful participation in an online course and essentially, denies the opportunity to succeed to those who do not possess this coveted knowledge of expected behavior.

Defining expectations becomes even more important in working with students who have had little or no experience with discussion board activity. Research with undergraduate students [15] suggests that taking an instructional approach to forum posting in the first learning module may help inform students of discussion expectations. This approach may also work well for adult learner populations, many of whom are returning to the academic setting after years of professional experience,

In practice, clear guidelines can improve student outcomes. A positive correlation was found between stated guidelines for discussion posting and students perceived learning in SUNY's SLN [9]. Other researchers, such as [21], report that courses whose instructors who did not post clear guidelines on the length, quantity and content of posts resulted in discussions that lacked academic quality. In these cases students' posts floundered and consisted mostly of asking for help on other parts of the course. Other researchers [40] have found that increasingly detailed guidelines and structure were correlated with increased threading and interaction. These researchers also found that increasingly detailed evaluation guidelines and the presence of a rubric were correlated with increased numbers of posts per student.

\section{G. Presence of Feedback}

According to the Chickering and Gamson's Seven Principles for Good Practice in Undergraduate Education, good practice involves providing feedback to guide student learning [4]. Other researchers [10] suggest that meaningful discussion can be effectively facilitated by grading discussion activity.

In practice, several researchers report found that the use of the course grades is positively correlated with discussion board activity. In courses where feedback was "timely and substantive" there were higher levels of dialogue [21]. In courses where discussion boards were not assessed (no numerical or letter grade), there were many non-participating students throughout the semester [21]. However, in courses where only quantity of posts was measured, the quality of posts did not meet instructors' expectations [21]. According to [9], grade weight for discussion is positively correlated with students' quantity of posts, perceived learning and perceived student-student interaction. Other researchers report that courses with a graded discussion board have significantly higher quantities of student posts than courses that do not [46]. Interestingly, the work of [24] indicates a positive correlation between the percentages of the course grade derived from discussion participation with student satisfaction, perceived learning, perceived interaction with the instructor and perceived interaction with their peers.

\section{METHODS}

Fourteen online undergraduate Mathematics courses (33 course sections) offered by the Center for Distance Learning at Empire State College were observed for the entire duration of their delivery. Courses were delivered over a 15 week semester, beginning in January 2008. Each discussion board, in addition to course syllabi, private folders and grade book were observed during this time period. The result was an analysis of 11,596 posts made over 335 message boards. Only course discussion boards were analyzed. Not included in the analysis were the Ask a Question Board, Student Lounge and the Icebreaker discussion. Small group discussions were included in the analysis, however discussions used 
as laboratory workspaces (i.e. gathering data and preparing a report) were not included. The distinction between these two items was made based on whether the goal was discussion (included) or to prepare a lab/homework report (not included). Discussion boards were observed and quantified two weeks after their due date to capture late posting students' contributions.

\section{A. Student Participation}

Student participation was calculated by the number of students participating in a message board, divided by the number of students enrolled in the course as the time of the message board.

$$
\text { Student participation }=\frac{\# \text { of students participating in discussion }}{\text { \#of students enrolled inthe course }}
$$

\section{B. Quantity of Student Postings}

The quantity of student posts for each discussion board was calculated as the number of student posts on a message board, divided by the number of students participating in the message board.

$$
\text { Quantity of student posts }=\frac{\# \text { of student posts }}{\text { Students participating in the discussion }}
$$

This gave an indication of how many posts students were making on discussion boards and in the course overall, when they chose to participate.

\section{Quality of Student Postings}

Transcript analysis was conducted to assess the quality of posts. Student and instructor posts were codes as Educationally Valuable Talk (EVT) or Educationally Less Valuable Talk (ELVT) according to the definitions set forth by [47]. The percent of educationally valuable talk was calculated by dividing the number of EVT posts by the total number of posts.

$$
\text { Quality }=\frac{\# \text { of EVT posts }}{\text { total \#of posts }}
$$

\section{Extent of Threading}

For the purposes of this study, three conversation styles were defined (Fig. 1). The "speak" style was defined by an original post to which there was no reply. The "speak-reply" style was defined by an original post which receives only one reply or several replies only one layer deep. The "discuss" style was defined by an original post, which contained replied at least two layers deep.

\begin{tabular}{|l|l|}
\hline Conversation Style & Example \\
\hline Speak & Math is Great...Posted by Mary \\
\hline Speak-reply & Math is Great...Posted by Mary \\
& Re: Math is Great...Posted by Bob \\
& Re: Math is Great...Posted by Cindy \\
\hline
\end{tabular}




\begin{tabular}{|c|c|}
\hline Discuss & $\begin{array}{l}\text { Math is Great...Posted by Mary } \\
\text { Re: Math is Great...Posted by Bob } \\
\text { Re: Math is Great...Posted by Mary } \\
\text { Re: Math is Great...Posted by Cindy }\end{array}$ \\
\hline
\end{tabular}

Figure 1. Conversation Style Categories

\section{E. Instructor Presence}

The quantity of posts made by an instructor to a discussion board was divided by the number of active students. This was done in order to facilitate comparisons between classes with different enrollments. It was decided the participating students was a more accurate measure of how "response" instructors were to student posts.

$$
\text { Instructor presence }=\frac{\# \text { of instructor posts }}{\# \text { of students participating indiscussion }}
$$

\section{G. Expectations \& Guidelines}

The course syllabi and discussion board directions were examined for evidence of guidelines regarding the quantity and quality of posts students should make. Guidelines were scored as present (1) or absent $(0)$.

\section{H. Presence of Feedback}

The course grade book and private folders for students were examined to reveal evidence of discussion board evaluation. Evaluation of students' discussion board posts via email was not included because it was not possible (nor desirable) to search faculty email accounts for this information. Evaluation was scored as present (1) or absent (0).

\section{RESULTS}

The results in this paper describe overall trends exhibited by the thirty three course sections. Further analysis which compares multiple sections of the same course or multiples courses taught by an instructor could be conducted, but are beyond the scope of the results presented and discussion in this paper.

\section{A. Participation}

Participation in discussion boards varied between courses and between different sections of the same course (Fig. 2). The proportion of enrolled students who participated in discussions, averaged for each course section $(n=33)$ ranged from .94 to .40. Using Pearson's Correlation Coefficient, a significant positive correlation was found between participation and the instructor presence $(p<.01)$. Similarly, a significant positive correlation was also found between with presence of feedback $(\mathrm{p}<.001)$ and with guidelines describing instructor expectations for quality posts $(\mathrm{p}<.01)$. 


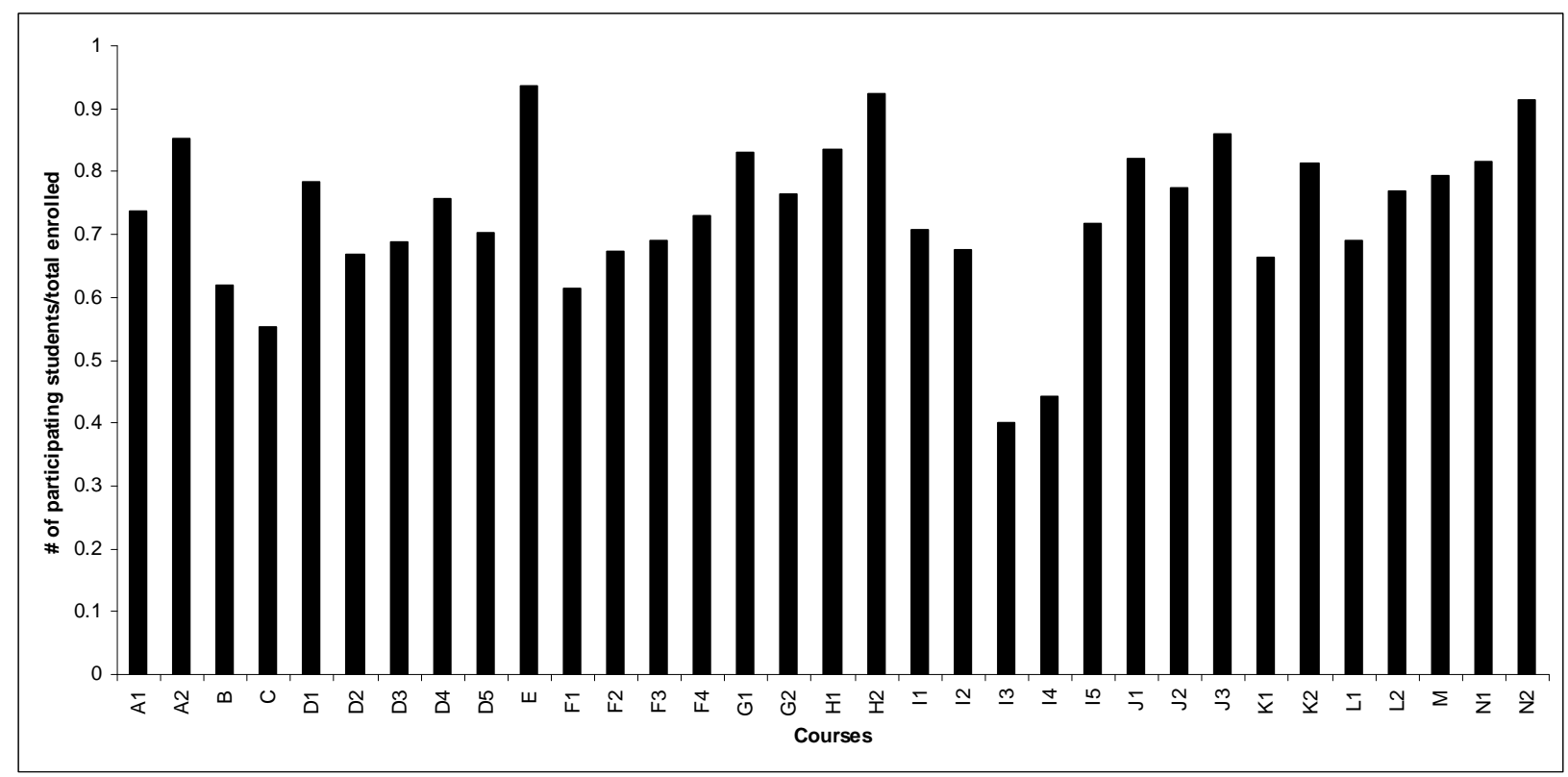

Figure 2. The Proportion of Students Participating in Discussion Boards. Courses are Designated by Letters and Course Sections are Designated by Numbers. For example, G1 Represents Section 1 of Course G.

\section{B. Quantity of Student Postings}

The quantity of student posts varied from a low of 1.424 messages/participating student to a high of 4.75 messages/participating student. There were considerable differences both between courses and between different sections of the same course (Fig. 3). Pearson's Correlation coefficient revealed a significant positive correlation between the quantity of student posts was positively correlated with instructor presence $(\mathrm{p}<.05)$, with presence of feedback $(\mathrm{p}<.01)$ and with guidelines describing instructor expectations for quality posts $(\mathrm{p}<.001)$. Interestingly, the quantity of student posts was not correlated with the presence of guidelines describing the expectations for quantity of posts. 


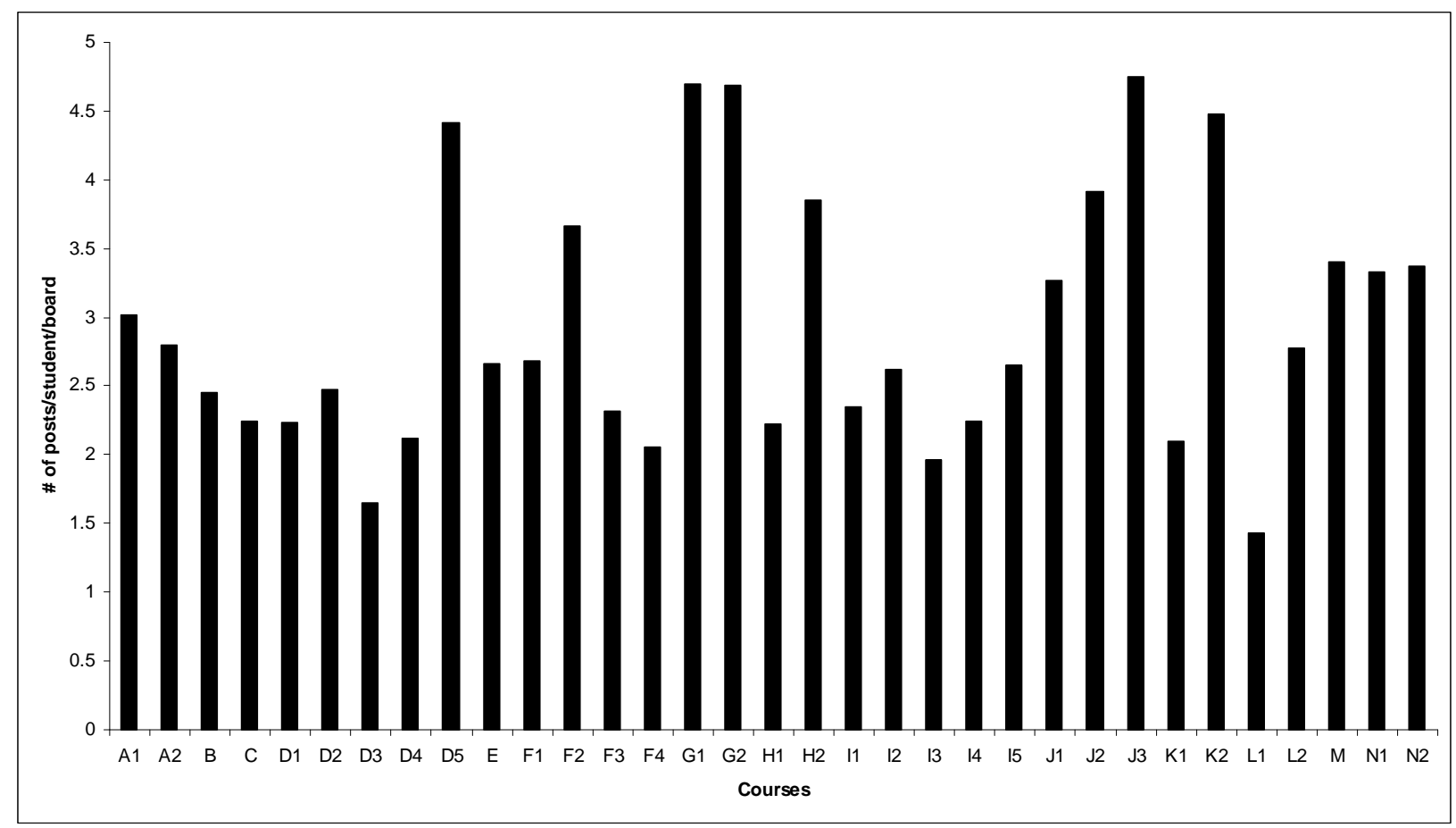

Figure 3. The Average Number of Posts per Participating Student per Discussion Board.

\section{Quality of Student Postings}

The proportion of the total posts that contained educationally valuable talk varied from a low of .27 to a high of .78 (Fig. 4). Quality was positively correlated with presence of feedback $(p<.025)$. Quality of student posts was not correlated with instructor presence or guidelines for quality or quantity.

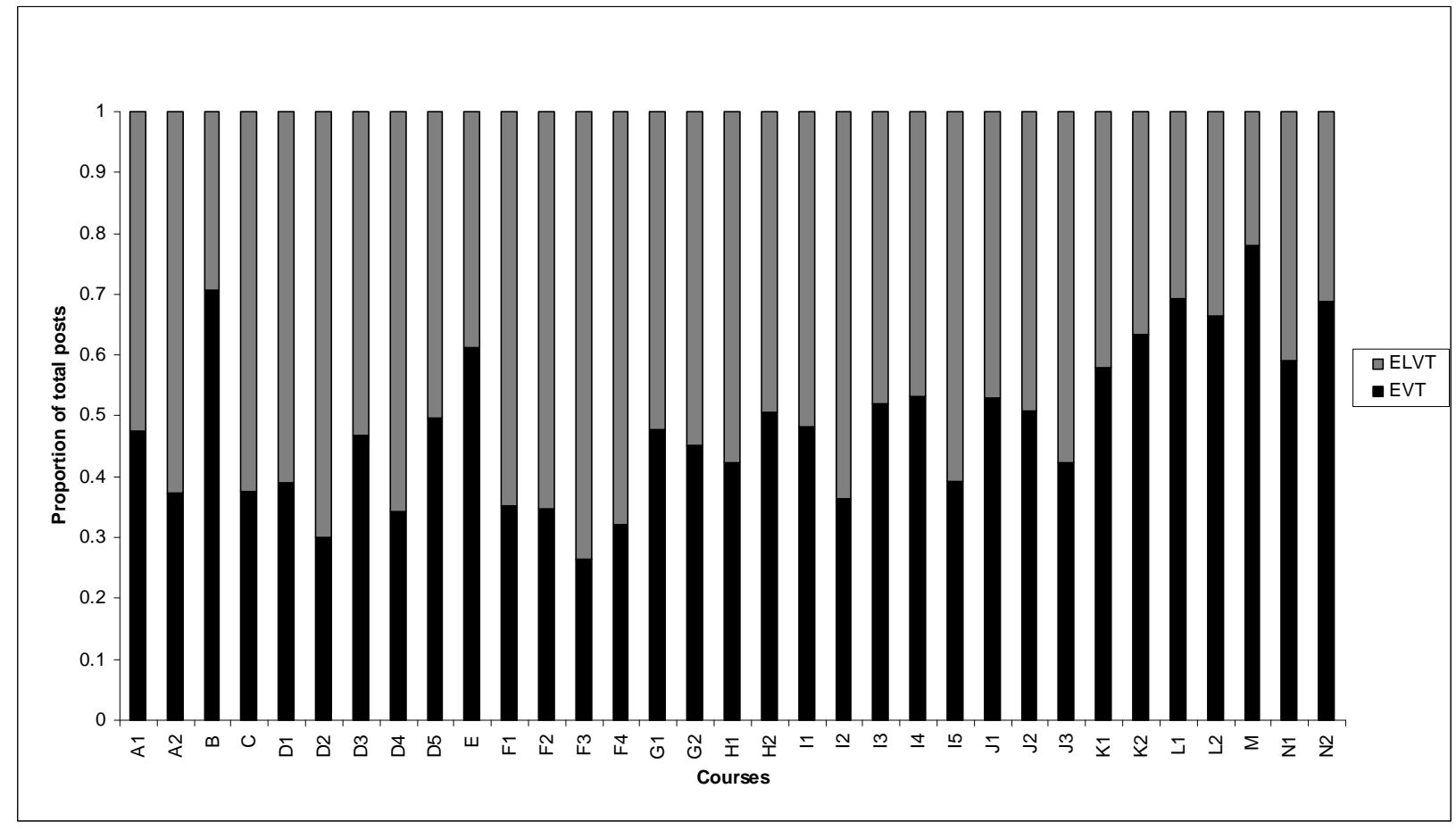

Figure 4. Quality of Posts was Determined by Criteria Set Forth by Uzuner’s EVT/ELVT Criteria [43]. 


\section{Extent of Threading}

The extent of threading is presented in Figure 5. The percent of initial threads that resulted in a discussion was positively correlated with instructor presence $(\mathrm{p}<.05)$, with Evaluation (use of grade book) $(\mathrm{p}<.05)$ and with guidelines describing instructor expectations for quality posts $(\mathrm{p}<.05)$. The percent of 'speak' posts was negatively correlated with the responsiveness of instructor posts $(p<.05)$, with guidelines describing instructor expectations for quantity posts $(\mathrm{p}<.025)$ and with guidelines describing instructor expectations for quantity posts $(\mathrm{p}<.05)$.

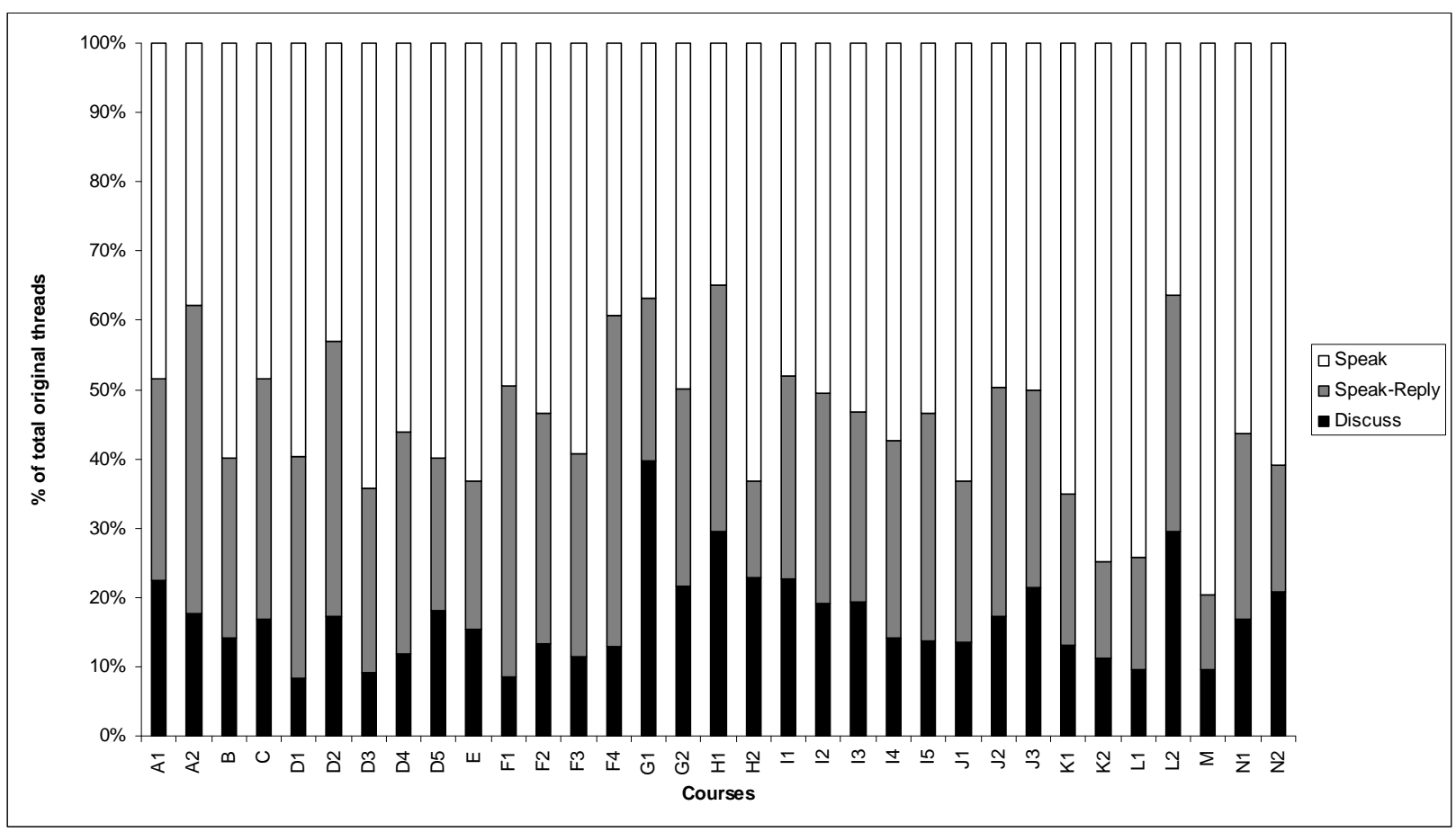

Figure 5. The Percentage of Conversation Style on Discussion Boards

\section{E. Instructor Presence}

Instructors varied in their approach to discussion boards (Fig. 6). Some instructors were very responsive, such as G1 with an average responsiveness of 2.62 messages per participating student. Other instructors hardly posted during the entire semester. For example, J2 posted only 1 message during the course (.01 messages/student). 


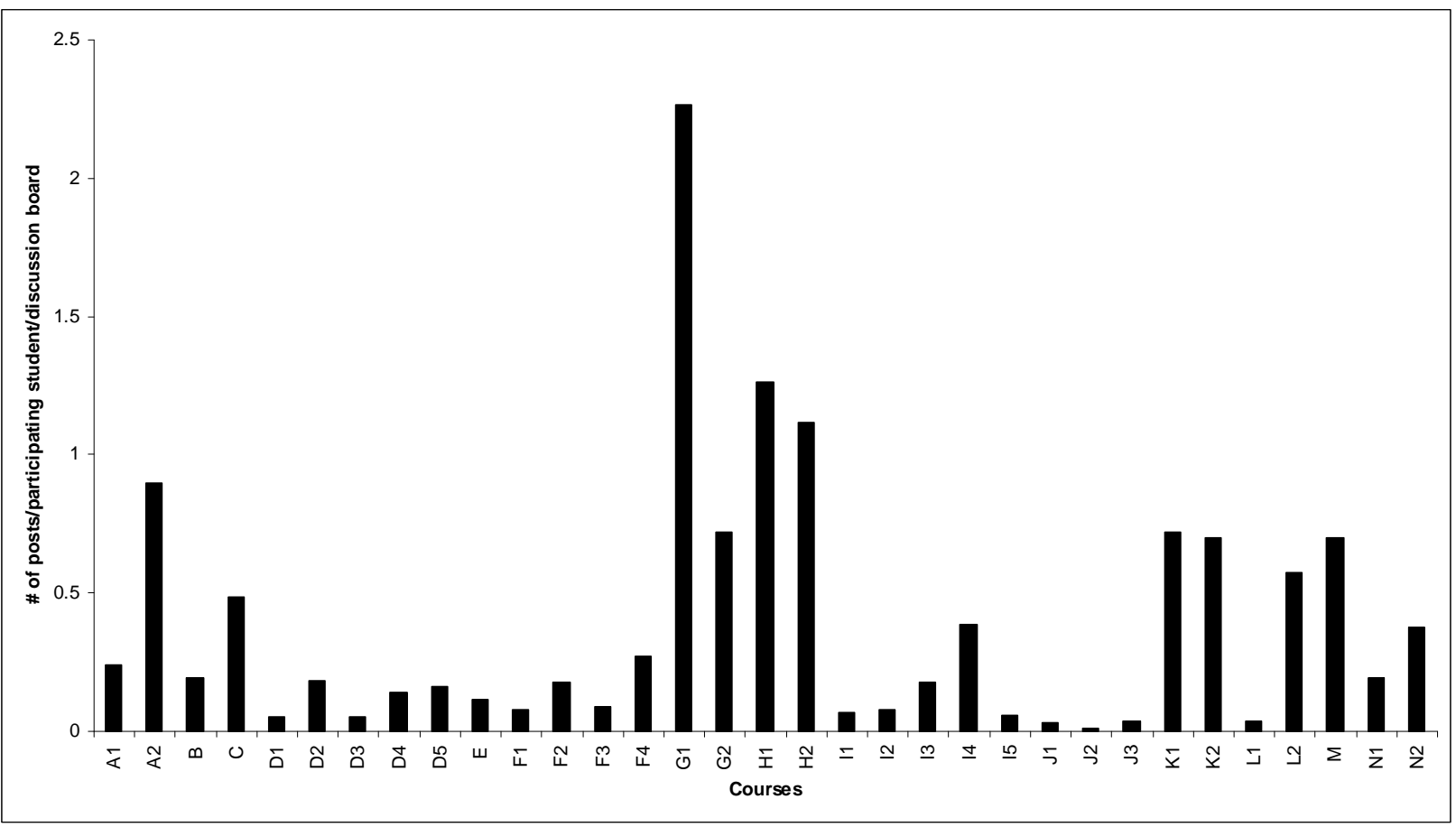

Figure 6. Instructor presence as determined by the number of instructor posts per participating student.

\section{F. Expectations \& Guidelines}

Seventy-nine percent of CDL Mathematics courses contained guidelines for the number of student posts. In $52 \%$ of these courses, the standard was set to 1 original post and 2 replies.

Only $27 \%$ of courses contained guidelines for what is meant by a quality post. These guidelines usually addressed the presence of critical thinking in the post and/or providing substantive content that could increase understanding of the subject matter. One course contained a discussion rubric however, it was not used.

\section{G. Presence of Feedback}

Evaluation of students' discussion board posts was provided in 15 out of 33 course sections. No feedback regarding discussion board posts provided to students in the Private Folders. Thus, the 15 course sections which did provide feedback utilized the grade book as the mechanism for communicating feedback and evaluating student discussion posts.

\section{DISCUSSION}

In this paper, the development and application of a metric is presented which is suitable for analyzing discussion board use patterns in large data sets. This multi-factor metric provides valuable information for researchers and practitioners. As a tool for research, this metric can be used to analyze discussion board use patterns in large data sets. This provides an advance over previous studies which have typically utilized cross-case study [21] or single case study approaches [18, 22]. For practitioners, particularly course supervisors, this metric may be used to compare discussion board use patterns within a distance learning program's set of online courses. 
This study, distinguishes participation from students' quantity of posts. This is an improvement over previous studies which often use these terms synonymously, thus obscuring distinctions between the percent of enrolled students which actually participate in discussions and measures of how frequently students post once they decide to participate. Learning orientation may also play a role in determining which type of learners may engage with and benefit from discussion board activities. In order to engage in mathematical discussions which create knowledge, students must be willing to venture mathematical ideas in a public forum and interested in socially constructing knowledge. Three models suggested by [48] may affect learner's orientation towards engagement in discussion boards. Independent learners typically master concepts through solitary study while interactive learners tend to prefer one-to-one or one-to-many conversations. The collaborative learner may be most likely to engage in shared knowledge building in discussion boards.

Admittedly, this study assumes that discussion participation is synonymous with the decision to post to a discussion board. Some authors have argued that discussion board participation should be more broadly defined to include both posting and viewing behavior. The work of [47] suggests that "hits," rather than discussion board posts are more predictive of students' learning. This is not surprising, however, because highly motivated students may have high login rates, as well as high end of course quiz grades. The work of [29] also suggests that "pedagogical lurking" can result in self-reported learning. Future studies may wish to investigate the role that lurking plays in students' valuation of discussion boards as a learning tool.

Applying the classification of Educationally Valuable Talk (EVT) and Educationally Less Valuable Talk (ELVT) developed by [43] is an improvement over previous rubrics and content analyses for discussion transcripts. Coding discussion posts as EVT vs. ELVT is intuitive and straightforward. Transcript analysis can be conducted efficiently, while still retaining valuable information about the nature of the discussion that took place. Although we may envision a dialogue composed entirely of EVT as desirable, in practice, this is neither realistic nor desirable. ELVT posts that contribute to the development of a learning community, through trust, acknowledgment and empathy may not move a discussion along educationally, but they move the class towards building community $[5,6]$. These elements open the doors for future "risk taking" in the course and build a support network for students within the course.

This study proposes a new way of characterizing the extent of threading in threaded discussions. This measure is an improvement over previous attempts to measure interaction patterns. It neither blurs the distinction between unanswered, acknowledged, and discussion-generating posts $[18,21]$ nor does it involve the use of overly time consuming data analysis tools $[44,45]$ which can be useful for theoretical research, but impractical for action research. Realistically, in a discussion, some comments may go unanswered. Ideally, the percent of unanswered posts would be as small as possible. In some courses, the percent of unanswered posts was less than $40 \%$. Instructors in these courses posted often to the discussion board and their style of posting often involved affective and supportive comments, followed by probing questioning techniques [49]. In contrast, other instructors who posted often to the discussion boards, but who lacked the warmth and enthusiasm, did not generate the extent of threading seen in other courses.

The results of this paper confirmed what we believe to be best practices in higher education [4]. Student participation, student quantity of posts and extent of threading were positively correlated with instructor presence, presence of feedback and guidelines for quality posts. The measure of quality of posts was correlated with presence of feedback. These results are not surprising, but rather provide further evidence which supports previous studies which suggest that the presence of feedback is an important factor in discussion facilitation $[9,21,46]$ as is instructor presence $[3,8,9,24,25]$ and structuredness [15, 40]. 
Instructor presence was positively correlated with participation rates, quantity of student posts and discussion threading. These results suggest that instructors who are present, attentive and active in discussion boards can facilitate student participation in discussion forums. The results here do not support the view that increased instructor posts tend to 'shutdown' a discussion [22, 23]. Instead, this finding is similar to the conclusions drawn by [14], who suggested that instructors who demonstrate presence, without taking over the discussion, were able to effectively facilitate discussions. Interestingly, instructor participation was not correlated with the quality of student posts, suggesting that instructor posts do not necessarily function to re-focus or deepen the discussion. In some cases, it was noted that instructors' posts tended to stray off-topic and become more conversational than educational. These findings are consistent with the work of other researchers who found that the majority of faculty posts were those with no academic content (other, administrative, and affective) [20].

Developing rich discussions in online mathematics courses is an area not well represented in the literature. A need exists for discipline specific study, particularly with respect to the learning and teaching of mathematics at a distance. Many students and faculty may be familiar with a transmission model of math instruction. In an online setting, the transmission (direction instruction) model would be equivalent to students reading content, assimilating this content into their cognitive scheme and then performing mathematical tasks with mastery. This model assumes the exposure is sufficient for learning. While some mathematically talented students may be able to learn Mathematics in this way, these students certainly do not make up the majority of undergraduate liberal arts students.

Some researchers have noted that online mathematics courses have higher attrition rates than online courses in other disciplines and that these differences are not mirrored in the face to face setting [50]. These authors suggest that part of the reason for high attrition rates is that the interaction needed to master mathematical skills is missing from asynchronous models of discussion [50]. Other studies have attempted to overcome these difficulties by incorporating synchronous, chat-based, tools [51]. However [52] note that many chat forums lack the tools needed to use mathematical notation, thus providing another obstacle for the learning of mathematics in online discussions. These authors conclude that 'mathematics is not suited for online learning.'

We take a different viewpoint and suggest that capacity for learning management systems to support a greater number of one-to-one and one-to-many communications than in a face-to-face classroom provides an increased opportunity for the communication and learning mathematics. That the challenge for improving mathematical communication, particularly through asynchronous discussion boards, is to first develop tools with which we can measure current use patterns. The development of such tools, such as the metric presented in this paper, hold promise for being able to measure how discussion board use patterns change with particular changes in course structure, teaching style or other parameters targeted for course improvement. Further research that is discipline specific to mathematics will add to the body of knowledge in a relatively undeveloped area of research within online learning pedagogy.

\section{CONCLUSIONS}

A multi-factor metric was developed and applied to 33 sections of undergraduate Mathematics courses. The metric quantifies student participation, quantity of student posts, quality of posts, extent of threading, instructor presence, guidelines and presence of feedback. The indices presented here provide a significant improvement over previous studies in their use with large data sets and thus, pragmatic application for

researchers and practitioners. This work confirms the results of earlier work which suggest that the presence of guidelines, feedback and instructor presence is correlated with greater student participation, quantity of posts, quality of discussion and extent of threading. Lastly, discussion board use patterns in 
online mathematics courses have not been well explored in the literature and further work in this area is encouraged.

\section{REFERENCES}

1. Garrison, D. R., T. Anderson, \& W. Archer. Critical inquiry in a text-based environment: Computer conferencing in higher education. The Internet and Higher Education 2(2/3): 87-105, 1999.

2. Swan, K. Learning effectiveness online: What the research tells us. In J. Bourne and J. C. Moore (Eds.) Elements of Quality Online Education, Practice and Direction. Needham, MA: Sloan-C, 1345, 2003.

3. Shea, P. J., A. M. Pickett, \& W. E. Pelz. A follow-up investigation of 'teaching presence' in the SUNY learning network. Journal of Asynchronous Learning Networks 7(2): 61-80, 2003. www.sloan-c.org/publications/jaln/v7n2/pdf/v7n2 shea.pdf.

4. Chickering, A. W. \& Z. F. Gamson. Seven principles for good practice in undergraduate education. The American Association for Higher Education Bulletin 39(7): 3-7, 1987. http://honolulu.hawaii.edu/intranet/committees/FacDevCom/guidebk/teachtip/7princip.htm.

5. Rourke, L., T. Anderson, D. R. Garrison \& W. Archer. Assessing Social Presence in Asynchronous Text-based Computer Conferencing. Journal of Distance Education 14(2): 50-71, 1999.

6. Brown, R. E. The process of community building in distance learning classes. Journal of $\begin{array}{lllll}\text { Asynchronous } \quad \text { Learning } & \text { Networks }\end{array}$ www.sloanconsortium.org/publications/jaln/v5n2/pdf/v5n2_brown.pdf.

7. Rovai, A. P. A constructivist approach to online college learning. Internet and Higher Education 7: 79-93, 2004.

8. Fredericksen, E., A. Pickett, P. Shea, W. Pelz \& K. Swan. Student satisfaction and perceived learning with online courses: Principles and examples from the SUNY Learning Network. Journal of Asynchronous Learning Networks 4(2): 7-41, 2001. $\quad$ www.sloanconsortium.org /publications/jaln/v4n2/pdf/v4n2 fredericksen.pdf.

9. Jiang, M. \& E. Ting. A study of factors influencing students' perceived learning in a web-based course environment. International Journal of Educational Telecommunications 6(4): 317-333, 2000.

10. Greenlaw, S. A. \& S. B. DeLoach. Teaching critical thinking with electronic discussion. The Journal of Economic Education 34(1): 36-53, 2003.

11. Meyer, K. A. The ebb and flow of online discussions: What Bloom can tell us about our students' conversations. Journal of Asynchronous Learning Networks 9(1): 53-63, 2005. www.sloanc.org/publications/jaln/v9n1/pdf/v9n1_meyer.pdf.

12. Muilenburg, L. \& Z. L. Berge. A framework for designing questions for online learning. DEOSNEWS 10(2): 2000. www.emoderators.com/moderators/muilenburg.html.

13. Vygotsky, L. S. Mind and society: The development of higher mental processes. Cambridge, MA: Harvard University Press, 1978.

14. Bloom B. S. Taxonomy of Educational Objectives, Handbook 1: The Cognitive Domain. New York: David McKay Co Inc., 1956.

15. Aviv, R. Educational performance of ALN via content analysis. Journal of Asynchronous Learning Networks 4(2): 53-72, 2000. http://www.sloanconsortium.org/publications/jaln/v4n2/pdf /v4n2_aviv.pdf.

16. Meyer, K. A. Face-to-Face Versus Threaded Discussions: The Role of Time and Higher-Order Thinking. Journal of Asynchronous Learning Networks 7(3): 55-65, 2003. http://www.sloanconsortium.org/publications/jaln/v7n3/pdf/v7n3_meyer.pdf. 
17. Picciano, A.G. Beyond student perceptions: Issues of interactions, presence, and performance in an online course. Journal of Asynchronous Learning Networks 6(1): 21-40, 2002. http://www.sloanconsortium.org/publications/jaln/v6n1/pdf/v6n1_picciano.pdf.

18. Kay, R. H. Developing a comprehensive metric for assessing discussion board effectiveness. British Journal of Educational Technology 37(5): 761-783, 2006.

19. Anderson, T., L. Rourke, D. R. Garrison, \& W. Archer. Assessing teaching presence in a computer conferencing context. Journal of Asynchronous Learning Networks 5(2): 1-17, 2001. http://www.sloanconsortium.org/publications/jaln/v5n2/pdf/v5n2_anderson.pdf.

20. Blignaut, A. S. \& S. R. Trollip. Measuring faculty participation in asynchronous discussion forums. Journal of Education for Business 78(6): 347-353, 2003.

21. Dennen, V. P. From message posting to learning dialogues: Factors affecting learner participation in asynchronous discussion. Distance Education 26(1): 127-148, 2005.

22. Li, Q. Would we teach without technology? A professor's experience of teaching mathematics education incorporating the internet. Educational Research 45(1): 61-77, 2003.

23. Mazzolini, M. \& S. Maddison. Sage, guide or ghost? The effect of instructor intervention on student participation in online discussion forums. Computers and Education 40: 237-253, 2003.

24. Swan, K., P. Shea, E. E. Fredericksen, A. M. Pickett \& W. E. Pelz. Course design factors influencing the success of online learning. WebNet 2000 World Conference on the WWW and Internet Proceedings. San Antonio, Texas, October 30-November $4^{\text {th }}, 2000$.

25. Wu, D. \& S. R. Hiltz. Predicting learning from asynchronous online discussion. Journal of Asynchronous Learning Networks 8(2): 139-152, 2004. http://www.sloanconsortium.org/publications /jaln/v8n2/pdf/v8n2_wu.pdf.

26. Benigno, V. \& G. Trentin. The evaluation of online courses. Journal of Computer Assisted Learning 16: 259--270, 2000.

27. Hazari, S. Strategy for assessment of online course discussions. Journal of Information Systems Education 15(4): 349-355, 2004.

28. Roblyer, M. D. \& W. R. Wiencke. Design and use of a rubric to assess and encourage interactive qualities in distance courses. The American Journal of Distance Education 17(2): 77-98, 2003.

29. Dennen, V. P. Pedagogical lurking: Student engagement in non-posting discussion behavior. Computers in Human Behavior 24: 1624-1633, 2008.

30. Gulati, S. Compulsory participation in online discussions: Is this constructivism or normalization of learning? Innovations in Education and Teaching International 45(2): 183-192, 2008.

31. Kay, R. H. Using asynchronous online discussion to learn introductory programming: An exploratory analysis. Canadian Journal of Learning and Technology / La revue canadienne de l'apprentissage et de la technologie [online] 32(1): 2008. www.cjlt.ca/index.php/cjlt/article/view/64/61.

32. Nisbet, D. Measuring the quantity and quality of online discussion group interaction. Journal of eLiteracy 1(2): 122-139, 2004.

33. Bali, M. \& A. R. Ramadan. Using rubrics and content analysis for evaluation online discussion: A case study from an environmental course. Journal of Asynchronous Learning Networks 11(4): 19-33, 2007. http://www.sloanconsortium.org/publications/jaln/v11n4/pdf/v11n4 bali.pdf.

34. Marra, R. M., J. L. Moore \& A. K. Klimczak. Content analysis of online discussion forums: A comparative analysis of protocols. Educational Technology Research and Development 52(2): 2340, 2004.

35. Meyer, K. A. Evaluating online discussions: Four different frames of analysis. Journal of Asynchronous Learning Networks 8(2): 101-114, 2004. http://www.sloanconsortium.org /publications/jaln/v8n2/pdf/v8n2_meyer1.pdf.

36. Christopher, M., J. A. Thomas \& M. K. Tallent-Runnels. Raising the bar: Encouraging higher level thinking in online discussion forums. Roeper Review 26(3): 166-171, 2004.

37. Kramarski, B. \& N. Mizrachi. Online discussion and self-regulated learning: Effects of instructional methods on mathematical literacy. The Journal of Educational Research 99(4): 218-231, 2006. 
38. Meyer, K.A. The method (and madness) of evaluating online discussions. Journal of Asynchronous Learning Networks 10(4): 83-97, 2006. http://www.sloanconsortium.org/publications/jaln /v10n4/pdf/v10n4 meyer1.pdf.

39. Savage, L. B. Eliciting critical thinking skills through questioning. Clearing House 71(5): 291-293, 1998.

40. Gilbert, P. K. \& N. Dabbagh. How to structure online discussions for meaningful discourse: a case study. British Journal of Educational Technology 36(1): 5-18, 2005.

41. Meyer, K. A. Does feedback influence student postings to online discussions? Journal of Educators Online 4(1): 1-17, 2007.

42. Benigno, V. \& G. Trentin. The evaluation of online courses. Journal of Computer Assisted Learning 16: 260, 2000.

43. Uzuner, S. Educationally valuable talk: A new concept for determining the quality of online conversations. Journal of Online Learning and Teaching 3(4): 400-410, 2007.

44. Pena-Shaff, J. B. \& C. Nicholls. Analyzing student interactions and meaning construction in computer bulletin board discussions. Computers and Education 42: 243-265, 2004.

45. Liu, C. C. \& C. C. Tsai. An analysis of peer interaction patterns as discoursed by on-line small group problem-solving activity. Computers and Education 50: 627-638, 2008.

46. Rovai, A. P. Strategies for grading online discussions. Journal of Computing in Higher Education 15(1): 89-107, 2003.

47. Ramos, C. \& E. Yudko. 'Hits' (not 'discussion posts') predict student success in online courses: A double cross-validation study. Computers and Education 50: 1174-1182, 2008.

48. Taylor, J. A. The evolution of online learning in bridging mathematics at a distance: The tension between learning needs, technological innovation and access restrictions in an Australian Regional University in Crossing the Bridge - Proceedings of the $10^{\text {th }}$ Australasian Bridging Mathematics Network, Auckland; UNITEC, pg 67-74, 2002.

49. Toledo, C. A. “Does your dog bite?" Creating good discussion questions for online discussions. International Journal of Teaching and Learning in Higher Education 18(2):150-154. 2006.

50. Smith, G. G. Student attrition in mathematics e-learning. Australasian Journal of Educational Technology 21(3): 323-334, 2005.

51. Loch, B. \& C. McDonald. Synchronous chat and electronic ink for distance support in mathematics. Innovate 3(3): 2007. www.innovateonline.info/index.php?view=article\&id=374.

52. Smith, G.G. \& D. Ferguson. Diagrams and math notation in e-learning: growing pains of a new generation. International Journal of Mathematical Education in Science and Technology 33(5): 681695. 